\title{
Interdependencies of Home Energy Storage between Elec- tric Vehicle and Stationary Battery
}

\author{
Thomas Kaschub ${ }^{1}$, Patrick Jochem, Wolf Fichtner \\ ${ }^{1}$ Thomas Kaschub (corresponding author), Chair of Energy Economics, Institute for Industrial Production (IIP), \\ at Karlsruhe Institute of Technology (KIT) (University of Karlsruhe), Building 06.33, Hertzstr. 16, \\ D-76187 Karlsruhe, Germany, Tel.: +49 721 608-44559, E-Mail:kaschub@kit.edu
}

\begin{abstract}
Decentralized power generation in private homes, especially by photovoltaic systems, is already common in Germany. The developments of batteries, both for electric vehicles (EV) and for stationary storage might lead to a mass market for those batteries. In this paper we evaluate the economy of stationary battery storage with photovoltaic system at home in the context of available EV and its integration level into the home. Therefore, we use an optimization model with one year detailed operation planning and maximize the net present value of the storage investment. We integrate restriction functions for the technical parameters of the storage systems and limit EV availability and usage on the basis of German mobility studies for single vehicles.

The results show, that an investment in a stationary battery system in combination with a photovoltaic system is profitable in Germany under the assumptions considered. The observed high numbers of battery cycles lead to strong requirements for battery lifetime, i. e. cycle stability and long calendar life time. Therewith, Li-ion batteries are a promising technology. In combination with an EV, the net present value of the stationary battery system is smaller when the EV is integrated into the home by controlled charging or the vehicle to home $(\mathrm{V} 2 \mathrm{H})$ concept, which allows discharging into the home system. The size of the EV battery, the availability at daytime and the load curve of the home are the main influencing factors for the profitability of the battery system.
\end{abstract}

Keywords: energy storage, EV, load management, photovoltaik, optimization model

\section{Introduction}

Worldwide developments in the last years, both in electric vehicles (EV) with lithium-ion based battery storage and in photovoltaic (PV) make it probable, that the market prices of batteries and PV systems will further decline, which lead in turn to an accelerated market penetration (and vice versa).
In Germany the prices for small PV systems fell only in the last four years from $4.36 € / \mathrm{W}_{\mathrm{p}}$ to $1.75 € / \mathrm{W}_{\mathrm{p}}$ [1] resulting in a renewable energy payment by law (EEG, [2]) of currently $17.02 \mathrm{ct} / \mathrm{kWh}$ (2013-01, [3]). These price reductions led to an undercutting of grid parity, as German electricity prices for homes, which rose already beyond $25 \mathrm{ct} / \mathrm{kWh}$, are higher than PV generation costs. Therefore, it is worthy to self- 
consume the generated electricity. Based on smart charging at home, it will become easy to self-consume the PV electricity through battery charging of a battery electric vehicle (BEV) or plugin hybrid electric vehicle (PHEV) on time. Implementing even a bidirectional smart charging device for discharging stored energy into the own home might support to increase selfconsumption and the profitability of the PV system. When discharging the vehicle battery for non-driving purposes, not only an unrestricted provision of mobility services should be taken into account but also an additional degradation of the battery.

Furthermore, the lithium-ion battery prices are assumed to fall in the next years due to higher market volumes and production developments [4]. Recently EV battery investment dropped to 380-500 €/kWh [7]. These will affect not only the prices for EV but also the prices for lithiumion based stationary home battery storages. Therefore, a possible market is seen for stationary battery storage (BS) to increase selfconsumption of PV. In Germany already more than 1.3 million PV systems with over $32 \mathrm{GW}_{\mathrm{p}}$ are installed [1], most of these systems are installed on the roof of private homes.

In the paper, we analyze the interdependencies between the storage capabilities of a stationary battery and the storage capabilities of $\mathrm{EV}$ at home. This includes controlled and uncontrolled charging as well as discharging for home consumption, also called vehicle to home (V2H). The analysis is done in a techno-economic manner. We consider a technical system setup and their restrictions in combination with the economic factors in an optimization problem.

First, we give an overview of our model used including key formulas and data. Second, we introduce the system configurations and the results. We conclude with a summary and outlook.

\section{Modeling Overview}

We use an optimization model to maximize the net present value (NPV) of BS and PV system including home power consumption. The target function (1) includes therefore the investment in BS and PV system. The BS investment is factorized with a factor of cycle degradation (80\% remaining capacity at end of life) and a factor for accelerated lifetime degradation due to times with high state of charge [8]. The underlying interest rate is $5 \%$. The yearly accounting includes costs for purchased electricity from the grid, maintenance costs of the BS, degradation costs of the EV battery by $\mathrm{V} 2 \mathrm{H}$ discharging and earnings for PV feed-in. Not included are the investment and other costs of the $\mathrm{EV}$, because it is assumed as independent investment for mobility reasons only.

$$
\begin{aligned}
& \max \boldsymbol{N P V} \\
& =-\operatorname{Inv} v^{B S} \operatorname{Cap}^{B S}\left(1+\frac{\boldsymbol{L} \boldsymbol{T}^{\boldsymbol{B S}, \text { red }}}{L T^{B S}}\right) \frac{1}{\operatorname{Deg}^{B S}} \\
& -I n v^{P V} \\
& +\sum_{a}\left(\left[\sum_{t}-\left(\boldsymbol{P}_{t}^{g r i d} D T C o_{a}^{g r i d}\right)\right.\right. \\
& -\mathrm{Co}^{\text {BS,Maint. }} \mathrm{Cap}+\left(1+\frac{\boldsymbol{L} \boldsymbol{T}^{\boldsymbol{B S}, \text { red }}}{L T^{B S}}\right) \frac{1}{\operatorname{Deg}^{B S}} \\
& -\sum_{t, E V}\left(\boldsymbol{P}_{t, E V}^{E V, V 2 H} D T C o^{\text {deg }}\right) \\
& \left.\left.+\sum_{t}\left(\boldsymbol{P}_{t}^{P V, \boldsymbol{g r i d}} p_{a}^{P V}\right)\right] /(1+i)^{a}\right)
\end{aligned}
$$

The resulting optimized NPV implies the best charging and discharging scheduling of the storage devices based on their technical capabilities, which are implemented in the model. For each time step the power balance of the home energy system has to be ensured (2).

$$
\begin{aligned}
& P_{t}^{H}+P_{t}^{B S, \text { charge }}+P_{t}^{E V, \text { charge }} \\
& =P_{t}^{P V, \text { self }}+P_{t}^{\text {grid }}+P_{t}^{B 2 H}+P_{t}^{V 2 H} \quad \forall t \in \mathrm{T}
\end{aligned}
$$


The resource scheduling is done for one whole year in time steps of a quarter hour. The principle of the resource scheduling for maximum selfconsumption is every year the same. Only the different solar radiation values would change. Therefore we use test reference years (TRY) [12]. The resource scheduling of one year is therefore assumed for all 20 years of the period of use that is considered for calculating NPV.

The model includes further equations that characterize the problem by given constraints and dependencies. We do not present them in this paper in detail, but shortly describe their relevance in the following. The equations are available upon request by the authors. The home electricity demand is integrated with a fixed load curve by real metered loads. The PV generation is given by historical solar radiation (DWD 2004) and an annual energy production. The self-consumption is limited by the load for home and charging processes. The EV is modeled based on real survey data out of the German Mobility Panel for conventional vehicles (MOP, [5]). It includes data of vehicle use for one complete week which is assumed for our analysis as typical for the whole year. Special trips (e. g. holiday) are not included as we assume another mode (e. g. rental car, aircraft, train). For smart charging upper and lower boundaries for the state of charge (SoC) are given (cf. [6]). Between those, the charging and discharging process is possible - limited by the available charging infrastructure and maximum charging power. The charging power for both battery devices is limited by a function $P_{\max }^{\text {charge }}(\mathrm{SoC})$, which reduces the charging power for high SoC (linear decrease above 75 \% SoC).

The stationary BS is limited by a lifetime of 7,000 cycles and 20 years. The calendar life time is reduced for high SoC according to [8] and included in the target function. Also selfdischarging (0.02/month) and a minimum charging gap $\left(0.05 \mathrm{P} / \mathrm{P}_{\text {nom }}\right)$ by the transformer output curve is considered. The SoC is calculated for each time step by an energy balance equation including charging efficiency of 0.94 .

With this model we have a mixed integer problem characterized by up to approx. 600 thousand variables.

\subsection{System Configurations}

The evaluation of the economic efficiency based on the net present value of the PV system and the stationary battery system (BS) is possible with three model configurations (cf. Tab. 1) that are optimized one after another.
Table 1: system configurations concerning PV and BS

\begin{tabular}{|c|l|c|c|}
\hline \multicolumn{2}{|c|}{ identifier } & $\begin{array}{c}\text { photovoltaic } \\
\text { system }\end{array}$ & $\begin{array}{c}\text { stationary } \\
\text { battery system }\end{array}$ \\
\hline A & Non & - & - \\
\hline B & PV & X & - \\
\hline C & PV\&BS & X & X \\
\hline
\end{tabular}

The integration of an EV has great influence on the whole system. To compare the interdependencies between EV charging and discharging and the stationary BS four configurations are evaluated:

I. $\mathrm{V} 2 \mathrm{H}$ "Vehicle to Home" means that $\mathrm{EV}$ is completely integrated into the home including controlled charging and discharging into home system

II. EVopt controlled (or smart) charging (no discharging) of the $\mathrm{EV}$ is integrated

III. EVstart charging of the EV starts always instantly after arriving at home

IV. EVno no EV available

In total we have twelve configurations of the system that can be compared. The integration of PHEV is possible, too. For this analysis we only included BEV in order not to increase complexity. Due to the reduced battery size of PHEV the results differ from those of BEV.

These configurations might not be mixed up with scenarios that define the parameters of the system components and prospections for future (e. g. electricity prices).

In order to consider the strong differences of home load curves and EV charging, the model is run with 50 different home load curves [11] and EV data [5].

\subsection{Reference Scenario}

We use one reference scenario for all system configurations. The period considered starts in 2016 and includes 20 periods until 2035. The electricity price is set to $25.1 \mathrm{ct} / \mathrm{kWh}$ in 2011 and extrapolated by an increase of $3 \%$ per year [9], which was true for the last years in Germany.

The investment for a small PV system is set to $1,904 € / \mathrm{kWp}$ by 2012 [1] and extrapolated by $-12 \%$ per year. In last six years the prices declined approx. $15 \%$ per year [1]. We do not assume earnings for PV feed-in according to EEG (German Renewable Energy Act) but fix $4 \mathrm{ct} / \mathrm{kWh}$ over all periods, which is less than current market prices at European Energy Exchange (EEX).

Current prices of EV batteries are lower than $500 € / \mathrm{kWh}$ [7] and even prices at $200 € / \mathrm{kWh}$ [11] are published. In contrast the prices given in the 
first German market overview of 21 stationary battery systems with Li-ion batteries [10] result in an average price at $2,790 € / \mathrm{kWh}$ (STDV $896 € / \mathrm{kWh}$ ) for usable battery capacity installed. As this market is in the first market stage and will grow fast, the prices are expected to fall rapidly. Therefore we assume $600 € / \mathrm{kWh}$ for the investment of the stationary battery system. The market overview [10] shows an average calendar lifetime of the systems by 19.7 years and 5,000 full cycles. Partial cycles are less degenerating. Therefore we assume 7,000 equivalent full cycles.

The sizing of the BS is done according to a small approximation tool for battery sizing. There we evaluated an optimal battery size with a factor of 0.422 by the total yearly electricity consumption (e. g. $0.422 \cdot 3.0 \mathrm{MWh}_{\mathrm{a}}=1.27 \mathrm{kWh}$ ).

\section{Results}

In all cases the aim is to maximize selfconsumption of the PV self-generated electricity, because electricity from grid is more expensive. The more flexible the power loads are, the more self-consumption is possible. In our model, the home consumption is assumed to be fix. With demand response (DR) it would be possible to shift loads of some home appliances [6]. As the effectiveness is unclear [12], we do not consider DR in the following. Here the flexible elements within the system are BS and the EV controlled charging or $\mathrm{V} 2 \mathrm{H}$-concept with controlled charging and discharging to home.

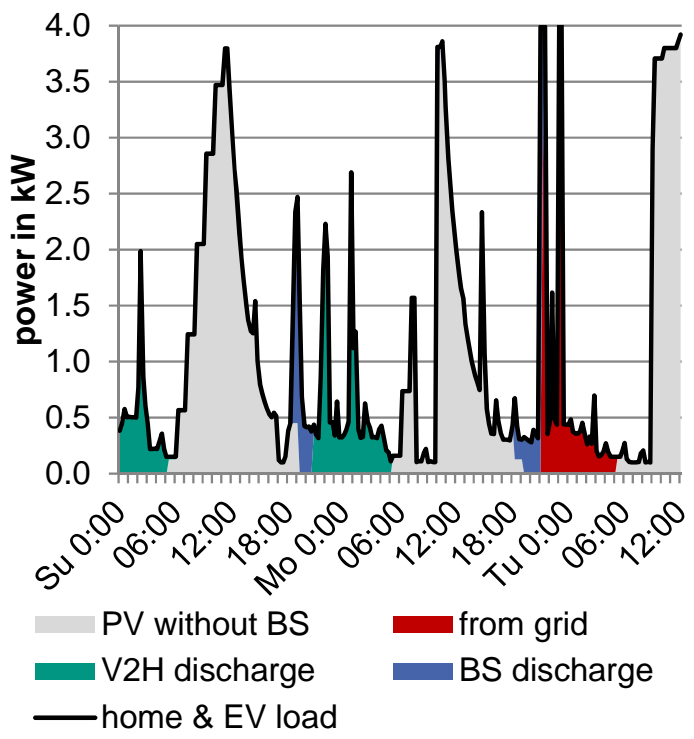

Figure 1: Power load of home and EV divided into power sources; V2H (exemplary home, spring)
Especially the charging of the EV has much influence on the load of the homes (cf. Fig. 1). One phase charging with maximum $3.5 \mathrm{~kW}$ is realized only, though it is responsible for the high load peaks. In Germany, the common three phase charging allows even a load of up to $22 \mathrm{~kW}$. Furthermore the electricity demand of the EV is often in the same dimension as all home appliances together.

In Fig. 1 the load curve of an exemplary home is displayed and the EV is fully integrated in the home energy management. Discharging from EV (green) is replacing more electricity from grid than the discharging from the smaller stationary battery storage (blue). In this example only one period in the night, the electricity was taken from the grid. The self-consumption to charge the BS is not displayed in Fig. 1.

The strong influence of EV integration into the home is more obvious in the results of NPV given in Tab. 2. In the second column the average NPV of all 50 analyzed stationary battery systems is given ${ }^{1}$. The three right columns show the share of positive NPV of the analyzed system components. We differentiate here for a single PV system investment, a single stationary battery system (BS) ${ }^{2}$ investment and a combined system investment (PV\&BS).

Table 2: net present value and share of positive investments for PV and BS system

\begin{tabular}{|l|c|c|c|c|}
\hline \multirow{2}{*}{} & $\begin{array}{c}\text { NPV in } \\
\text { average }\end{array}$ & \multicolumn{3}{|c|}{$\begin{array}{c}\text { share of analyzed homes } \\
\text { with positive NPV for }\end{array}$} \\
\cline { 2 - 5 } & $B S$ & $P V$ & $B S$ & $P V \& B S$ \\
\hline V2H & $-24 €$ & $98 \%$ & $50 \%$ & $100 \%$ \\
\hline EVopt & $549 €$ & $98 \%$ & $94 \%$ & $100 \%$ \\
\hline EVstart & $1,042 €$ & $68 \%$ & $100 \%$ & $90 \%$ \\
\hline EVno & $862 €$ & $42 \%$ & $100 \%$ & $64 \%$ \\
\hline
\end{tabular}

In the configuration without $\mathrm{EV}(E V n o)$ the BS is in any evaluated home a positive investment. An $\mathrm{EV}$ at home without integration (EVstart, instant full charging) makes the investment of the BS even better, because of the higher energy consumption and a changed load curve. When we integrate the EV into the home with controlled charging (EVopt) or with discharging into home system $(\mathrm{V} 2 \mathrm{H})$, the investment of the BS is getting less

\footnotetext{
${ }^{1}$ The NPV of the BS is calculated by the difference of the combined NPV for PV\&BS (configuration C) and the NPV auf the sole PV system (B)

${ }^{2}$ In this case we assume that the PV system is already present and not considered in the NPV.
} 
attractive. For V2H only $50 \%$ of the evaluated homes would have a positive investment.

The investment of the PV system is in nearly all cases positive, when high storing capacities are present to increase self-consumption. In the configurations of EVstart and EVno the single PV system is in many cases not positive. But in comcombination with BS the combined system is in $20-32 \%$ more homes profitable. For an integrated $\mathrm{EV}$, the combined system is profitable in all cases, but only for one home analyzed the BS makes the PV investment profitable.

Table 3: share of self-consumption and life-cycle usage

\begin{tabular}{|l|c|c|c|}
\hline \multirow{2}{*}{} & \multicolumn{2}{|c|}{$\begin{array}{c}\text { share of self- } \\
\text { consumption [\%] }\end{array}$} & $\begin{array}{c}\text { share of life- } \\
\text { cycle usage [\%] }\end{array}$ \\
\cline { 2 - 4 } & $P V$ & $P V \& B S$ & $P V \& B S$ \\
\hline V2H & 57 & 65 & 84.0 \\
\hline EVopt & 46 & 59 & 83.9 \\
\hline EVstart & 28 & 44 & 98.8 \\
\hline EVno & 23 & 38 & 96.0 \\
\hline
\end{tabular}

The higher the self-consumption, the more attractive is the investment in a PV system (cf. Tab. 2 and Tab. 3). In none of the analyzed system configurations the generally proclaimed $70 \%$ selfconsumption for homes with BS was reached in average. That is remarkable, as an optimization problem should reach higher self-consumption rates than simulation algorithms. In average, the BS increases PV self-consumption by 8 to $16 \%$. Already high rates due to controlled charging of the EV reduce the possibilities of the BS.

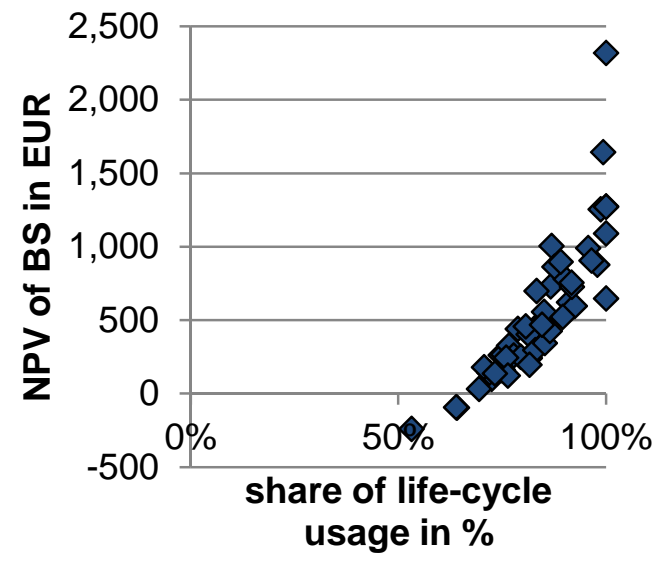

Figure 2: NPV of BS by life-cycle usage with EVopt

In all system configurations the average share of life-cycle use is high (cf. Tab. 3). For the case of controlled EV charging (EVopt) in Fig. 2 the connection of NPV and life-cycle usage is obvi- ous. Each item represents the result of one home. This result is coherent with the assumption, that high cycle numbers increase profitability of the BS investment.

In Fig. 3 an example of battery usage based on the state of charge (SoC) is given. We see a daily cycle but short times of high SoC. This is comprehensible, because high SoC reduce calendar life time of the battery.

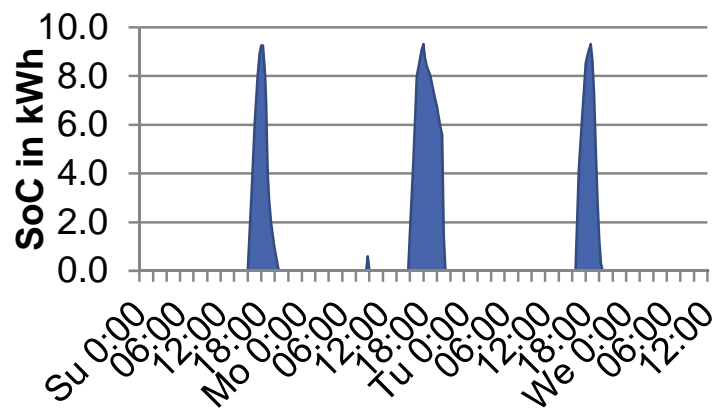

Figure 3: State of Charge of the stationary battery; V2H (exemplary home, spring)

The profitability of PV system and stationary BS is investigated further. Fig. 4 shows the NPV both of the PV and the BS system. The dependencies between the investment of a PV system and BS seem to be complex. The shape of the points in Fig. 4 is more like a cloud than a straight line. Further analysis is needed to understand the dependencies.

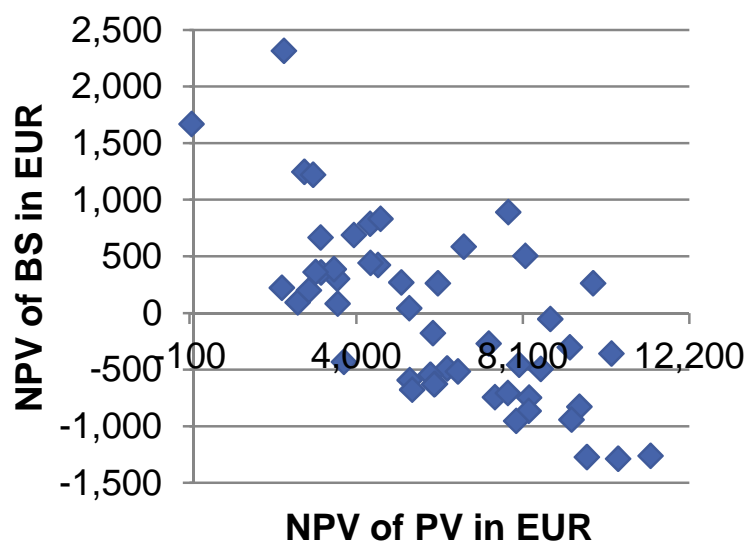

Figure 4: NPV of PV and BS with V2H

Looking at the impact on the grid an exemplary load curve of a home can give a first impression. Fig. 5 shows grid load in the case with stationary BS and with the possibility for EV to discharge into home and without both. Though the controlled charging of the EV can consume much of the PV generation during day time, at some point the battery is full and the self-generation is fed-in the 
grid. With sufficient stationary battery capacity this can be prevented.

Discharging of both, the BS and the EV, allows also during night time to be independent from the grid for most hours. Only during some times the grid connection is necessary. But in these cases also maximum power rates are needed (cf. Fig. 5 at Tuesday night). For reducing maximum power rates from grid additional regulations or incentives are necessary.

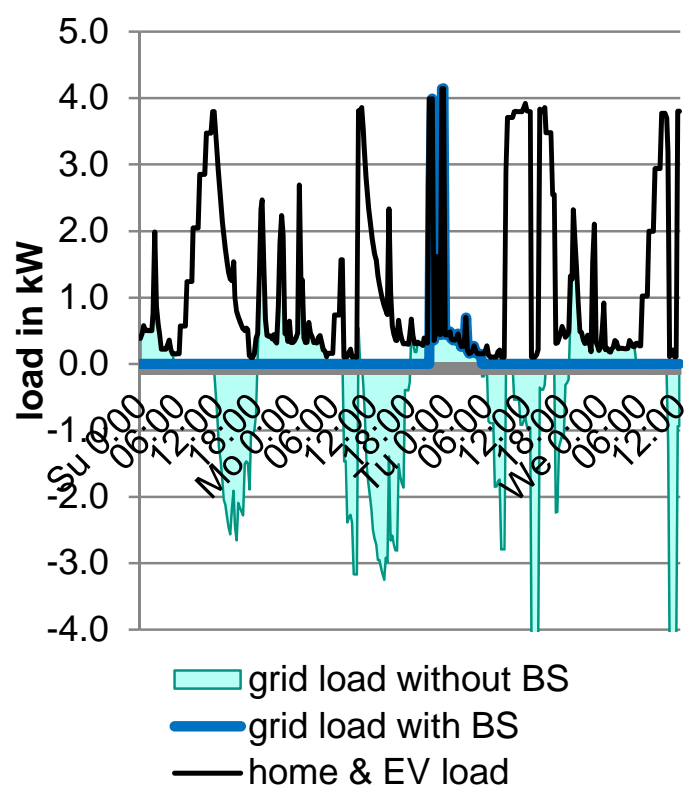

Figure 5: grid load with or without battery storage; V2H (exemplary home, spring)

Further strong influences that are not shown in the figures are seasons and the sun radiation which influences electricity earnings from the PV system.

\section{Conclusion}

In this contribution we analyze the interdependencies of electricity home storage between electric vehicles (EV) and stationary battery systems (BS). We use an optimization model for maximizing the net present value (NPV) of the BS. The NPV of the EV is not regarded, as we assume that the main purpose of the EV is mobility. The NPV of the PV system is however investigated, as the self-consumption rate strongly influences the profitability. As the market for BS in Germany is in its first stage, we analyze investments in the year 2016.

We show that in Germany the PV system alone and without the Renewable Energy Act (EEG) payments, is not profitable in any case. In combination with a BS more systems are profitable.
Batteries are used whenever possible to substitute power from grid in any system configuration. The self-generated power from PV is used especially for charging. Even the calculated degradation costs of the vehicle battery are lower than the price rate of the electricity supplier. Therefore, power consumption from the grid is reduced to a minimum. Integrating both, the $\mathrm{EV}$ and a stationary battery is less economical in most cases. Vehicle to home but also controlled charging have in general more impact to increase self-consumption of PV generation, than a small stationary battery, that is less economical in those cases. Especially when the EV charging is not controlled but starts immediately after arriving at home, a stationary battery is useful and has a positive NPV in most cases.

Therefore, we recommend including the investment in an EV with a controlled charging possibility or a BS when investing in a home based PV system in Germany in order to increase the profitability of the system. Further research is necessary in the parallel optimization of BS size, EV presence and PV system.

\section{Acknowledgments}

This research is part of the project iZEUS (01ME12013) which is funded by the German Federal Ministry of Economics and Technology (BMWi).

\section{References}

[1] Bundesverband Solarwirtschaft e.V. (BSWSolar), Statistische Zahlen der deutschen Solarstrombranche (Photovoltaik), Feb 2013, http://www.solarwirtschaft.de/fileadmin/medi a/pdf/2013_2_BSW_Solar_Faktenblatt_Photo voltaik.pdf, accessed on 2013-02-14

[2] EEG, Gesetz für den Vorrang Erneuerbarer Energien, 2012, BGBl. I S. 2730

[3] Bundesnetzagentur, Bestimmung der Vergütungssätze nach § 32 EEG für die Kalendermonate Februar, März und April 2013, http://www.bundesnetzagentur.de/SharedDoc s/Downloads/DE/BNetzA/Sachgebiete/Energi e/ErneuerbareEnergienGesetz/Verguetungssa etze_PVAnl/EEGVerg_FebApril2013.xls, accessed on 2013-01-10

[4] P. Jochem, J. Feige, et. al., Increasing Demand for Battery Applications, 6th International Renewables Energy Storage Conference and Exhibition, Berlin, Nov 2011

[5] D. Zumkeller, B. Chlond, et. al, The German Mobility Panel 2009/2010, German Federal 
Ministry of Transport, Building and Urban Affairs

[6] T. Kaschub, A.-G. Paetz, et. al., Lastmanagement mit intelligenten Haushaltsgeräten und Elektrofahrzeugen - eine modellgestützte Analyse, Tagungsband VDE Kongress, Stuttgart, 2012

[7] IEA, Global EV Outlook - Understanding the Electric Vehicle Landscape to 2020 International Energy Agency (IEA), 2013

[8] B. Lunz, Z. Yan, et al., Influence of plug-in hybrid electric vehicle charging strategies on charging and battery degradation costs, Energy Policy, 46(2012), 511-519

[9] BMWi, Zahlen und Fakten - Energiedaten: Nationale und Internationale Entwicklung, Bundesministerium für Wirtschaft und Technologie (BMWi), 2012

[10] M. Fuchs, Die Speicher kommen, photovoltaik, 10/2012, 84-87

[11] Wirtschaftswoche, http://www.wiwo.de/unternehmen/auto/dra matischer-preisverfall-e-auto-batteriendaimler-und-evonik-suchen-partner-fuer-litec/8350860.html, accessed on 2013-06-15

[12] A.-G. Paetz, T. Kaschub, P. Jochem, W. Fichtner, Load-Shifting Potentials in Households Including Electric Mobility - a Comparison of User Behaviour with Modelling Results, European Energy Markets Conference, 2013

[13] IIP, Technologies Database, Household load curves, Institute of Industrial Production, 2013

[14] DWD (Deutscher Wetterdienst), Testreferenzjahre von Deutschland für mittlere und extreme Witterungsverhältnisse TRY, 2004

\section{Authors}

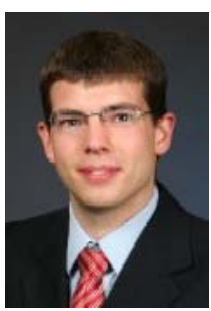

Thomas Kaschub is Research Associate at the Institute for Industrial Production (IIP) within the Chair of Energy Economics at the KIT since 2009. Before he finished his diploma in Mechanical Engineering at KIT. He focuses the topics electric mobility, local stationary battery storage, demand side management and energy system modeling.

Patrick Jochem is research group leader at the KIT-IIP, chair of energy

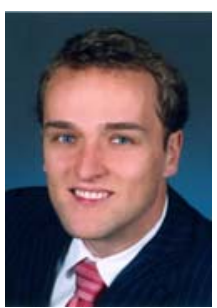
economics. In 2009 he received his $\mathrm{PhD}$ in transport economics from Karlsruhe University. He studied economics at the universities in Bayreuth, Mannheim and Heidelberg, Germany. His research interests are in the fields of electric mobility, and ecological economics.

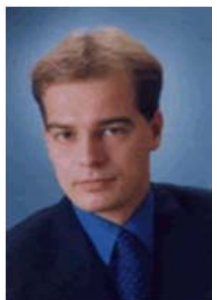

Wolf Fichtner is Director of the Institute for Industrial Production and the French-German Institute for Environmental Research. He is full professor and holder of the Chair of Energy Economics at KIT. His main areas of research are Energy System Modeling and the Techno-economic Analysis of Energy Technologies. 